\title{
“Mobbing" (Assédio Psicológico) no Trabalho: Uma Síndrome Psicossocial Multidimensional
}

\author{
Liliana Andolpho Magalhães Guimarães ${ }^{1}$ \\ Adriana Odalia Rimoli \\ Universidade Católica Dom Bosco
}

\begin{abstract}
RESUMO - No Brasil, o interesse pelo estudo do mobbing é recente. Nesta revisão, foram descritas as várias denominações dadas ao fenômeno, suas diferentes definições e características, visando uma delimitação teórico-conceitual. Buscou-se um aprofundamento da relação de semelhança entre os conceitos etológico e psicológico do mobbing, verificando-se que os mesmos guardam especificidades, sobretudo quanto às implicações evolutivas e ecológicas propostas pela etologia. A princípio, pode-se dizer que a semelhança entre os conceitos é somente morfológica. Uma abordagem evolucionista do mobbing no ambiente de trabalho, no entanto, poderia trazer novas contribuições para o seu entendimento como uma síndrome psicossocial multidimensional.
\end{abstract}

Palavras-chave: mobbing; assédio psicológico; assédio moral; trabalho; trabalhadores.

\section{Workplace Mobbing: A Multidimensional Psychosocial Syndrome}

\begin{abstract}
In Brazil only recently we had few studies on mobbing (psychological harassment at the workplace). This paper reports on a review of the literature in which definitions, characterizations and delimitations of mobbing were thoroughly examined with a view to a theoretical-conceptual definition of this phenomenon. Special attention was given to the similarities between the ethological and psychological concepts of mobbing. These concepts yield specificities, mostly when evolutionary and ecological implications are, according to the ethological model, taken into consideration. Apparently, the similarity between these two concepts is only morphological. However, an evolutionary approach to mobbing at the workplace may bring new contributions towards a better understanding of mobbing and see it as a multidimensional psychosocial syndrome.
\end{abstract}

Key words: mobbing; bullying; psychological harassment; work; workers.

"Tudo o que acontece uma vez, pode nunca mais acontecer, mas tudo o que acontece duas vezes, acontecerá certamente uma terceira".(Provérbio árabe)

Recentes pesquisas realizadas em alguns países europeus sugerem que a violência e o assédio psicológico têm afetado uma parte significativa da força de trabalho (Di Martino, 2002a; Leather, 2001; Paoli \& Merllié, 2001). O assédio psicológico no trabalho não é um problema exclusivo de determinados países, mas um fenômeno generalizado. No entanto, os dados disponíveis, os estudos realizados e as iniciativas adotadas advêm quase que exclusivamente dos países mais desenvolvidos, basicamente os europeus, Estados Unidos, Canadá, Japão, Austrália e Nova Zelândia, os quais possuem maiores recursos para investimentos em pesquisas desta natureza (Suárez, 2002).

No Brasil, o fenômeno, sob o rótulo assédio moral, vem sendo bastante estudado, sobretudo por juristas, havendo escassez de estudos realizados dentro do campo da saúde mental. Neste último, o debate ganha intensidade a partir do estudo realizado por Barreto (2000) intitulado "Uma Jornada de Humilhações". Posteriormente, o interesse pelo tema ganha força com a publicação do livro da psicanalista francesa Marie France Hirigoyen "Assédio Moral - a violência perversa do cotidiano", em 1998 na França, lançado no Brasil em maio de

1 Endereço: Rua Fernão Lopes, 544, Parque Taquaral, Campinas, SP, Brasil, 13087-050.E-mail: lguimaraes@mpc.com.br
2000. O reconhecimento do mobbing ${ }^{2}$ como uma nova causa de mal-estar e adoecimento no trabalho tem mobilizado pesquisadores da área da saúde mental ocupacional e foi objeto de um seminário especial, que antecedeu a programação do $27^{\circ}$ Congresso Internacional de Saúde no Trabalho, ocorrido em Foz do Iguaçu (PR) em 2002.

Nos novos modelos de análise da violência no ambiente de trabalho propostos pela Organização Internacional do Trabalho (OIT), suas manifestações físicas e psicológicas são igualmente consideradas, tendo sido dada importância aos atos de violência, considerados até o momento como "menos graves", tais como, o amedrontamento, a intimidação ou o assédio psicológico no trabalho. A partir desta proposta, rejeita-se a idéia de que a violência no ambiente de trabalho comporte unicamente fatores pessoais e passa-se a considerá-la como resultante de uma combinação de causas relativas às pessoas, ao meio ambiente, ao ambiente de trabalho e às condições organizacionais e contratuais do trabalho. Assim como às formas de interação entre os próprios trabalhadores, entre os clientes e os trabalhadores e entre estes e empresários (ILO, 2000).

A presença da violência no ambiente de trabalho implica em custos consideráveis para os indivíduos em termos de saúde e em relação a seu emprego e para a organização, dado

2 O termo mobbing será mantido em inglês, haja vista sua larga difusão na literatura especializada e leiga em vários idiomas, inclusive no português. 


\section{A. M. Guimarães e A. O. Rimoli}

o impacto causado pelo absenteísmo, baixa na produtividade e rotatividade de pessoal. $\mathrm{O}$ combate à violência no trabalho traz benefícios ao indivíduo, à organização e à sociedade como um todo (Hoel, Cooper \& Faragher, 2001).

Assim, o recente interesse frente ao problema não parece ser altruísta nem tampouco humanista, mas econômico. Segundo pesquisa realizada pelo Instituto Nacional de Saúde e Segurança Ocupacional (NIOSH, 2003), nos Estados Unidos, o custo total da violência no trabalho foi de US\$ 4 milhões, em 1992. No Canadá, as solicitações de indenização apresentadas pelos trabalhadores da área hospitalar aumentaram, desde 1985, em 88\%. Na Alemanha, o custo direto da violência psicológica em uma empresa com 1000 trabalhadores aumentou cerca de US\$ 112.000/ano (200.000 DM), além dos custos indiretos, orçados em US\$ 56.000 (Suárez, 2002).

Segundo Piñuel y Zabala e Cantero (2003), o mobbing no trabalho supõe a mais grave ameaça à saúde dos trabalhadores a ser enfrentada neste século. Além de graves sequielas que podem levar a outros problemas relacionados à saúde ocupacional, o mobbing tem afetado significativamente a saúde mental e física da população ativa e, também, a saúde organizacional.

\section{Denominações}

Diversas expressões têm sido utilizadas em diferentes países para designar o fenômeno. Na França - Harcèlement moral (assédio moral), Itália - molestie psicologiche, - na Inglaterra, Austrália e Irlanda - Bullying, Bossing, Harassment (tiranizar), nos Estados Unidos, Países nórdicos, bálticos e da Europa Central - Mobbing (molestar), no Japão - Murahachibu (ostracismo social), em Portugal - Coacção moral, nos países hispânicos - Acoso moral, acoso psicológico ou psicoterrorismo, no Brasil - Assédio moral, assédio psicológico, mobbing. A diversidade de expressões obedece à variedade cultural e à ênfase que se deseja colocar sobre algum dos múltiplos aspectos que levam à violência psicológica no trabalho. Se por um lado, essas diferentes denominações são uma riqueza, por outro, a tentativa de definição e descrição deste fenômeno em nível universal se vê comprometida e exige uma aproximação progressiva e um intercâmbio de conhecimentos, teorias, estudos e práticas transculturais.

Assim, os termos mobbing, bullying, assédio moral, assédio psicológico ou terror psicológico no trabalho têm sido utilizados como sinônimos para definir a violência pessoal, moral e psicológica, vertical (ascendente ou descendente) ou horizontal no ambiente de trabalho. No entanto, segundo Leymann (1990), o termo mobbing deve ser aplicado a adultos no contexto ocupacional, sendo uma forma de violência psicológica e o termo bullying aplicado a crianças e adolescentes, no contexto escolar, sendo, preferencialmente, uma forma de violência física.

Para Anderson (2001), ainda não foi adotada uma definição internacional sobre o mobbing no trabalho. Apesar disso, as definições elaboradas por parte de diversos pesquisadores e instituições internacionais foram circunscrevendo progressivamente este fenômeno. A falta de rigor inicial e de consenso na conceituação do mobbing provocou confusões e atrasos à sua adequada abordagem e enfrentamento.

\section{Definindo Mobbing}

A origem da palavra mobbing deriva da etologia. O conceito de mobbing foi proposto pela primeira vez por Niko Tinbergen e Konrad Lorenz em seus estudos com gaivotas e gansos.

No contexto etológico, pode-se definir o comportamento de mobbing como um ataque coletivo direcionado a um alvo considerado perigoso, por exemplo, um predador. Normalmente, este ataque envolve vários indivíduos da mesma espécie ou de espécies diferentes que tentam confundir o intruso com muitas vocalizações e ameaças a distância, afligindo-o com ataques sucessivos. Por outro lado, algumas aves, como gaivotas e tordos, durante o mobbing também podem defecar e vomitar no alvo (RSPB, s/d), apenas ocasionalmente podendo ocorrer contato físico.

Os estudos etológicos sobre mobbing têm sido realizados, principalmente, com aves (gaivotas, tordos, andorinhas do mar, tentilhões, entre outros). No entanto, este comportamento foi observado em esquilos (Owings \& Coss, 1977) e em algumas espécies de primatas, como: babuínos gelada (Theropithecus gelada; Iwamoto, Mori, Kawai \& Bekele, 1996), sagui-geoffroy (Callithrix geoffroyi; Passamani, 1995), Hanuman langur (Semnopithecus entellus; Srivastava, 1991) e sagüi-de-cara-suja (Saguinus fuscicollis nigrifons; Bartecki \& Heymann, 1987). Nestes estudos, os alvos dos ataques eram leopardos, gato-marajá (Leopardus wiedi), cobras e outros possíveis predadores. Para Richard (1985), os grandes primatas diurnos, gregários e que vivem nas florestas são incapazes de manterem-se despercebidos, portanto, respondem ao predador fugindo ou apresentando mobbing.

$\mathrm{O}$ comportamento de mobbing pode ser considerado adaptativo $^{3}$ já que traz consequiências positivas para seus atores: principalmente a proteção da prole contra predadores (Alcock, 1989). No entanto, os indivíduos ao atacarem um predador estão sujeitos a serem predados ou sofrerem algum tipo de ferimento ou mesmo gastarem tempo e energia que poderiam ser utilizados em outras atividades. Assim, para ser considerado um comportamento adaptativo, deve haver um benefício mínimo (ganho em aptidão) que exceda seus custos (perda em aptidão) (Alcock, 1989).

Apesar do comportamento de mobbing estar fortemente relacionado, principalmente nas aves, à estação reprodutiva (Alcock, 1989), indicando sua importância para a defesa dos ovos e dos filhotes recém-nascidos, outros benefícios deste comportamento foram sugeridos: avisar os indivíduos (da mesma espécie ou não) da presença de um predador, familiarizar os jovens e ensiná-los a identidade, o comportamento e a localização de seus possíveis inimigos (Garavaglia, 2000; Passamani, 1995) e se "auto-promover" mostrando sua coragem, seu bom estado de saúde e suas capacidades reprodutivas (Garavaglia, 2000). O comportamento de mobbing tem sido considerado parcialmente aprendido e parcialmente "instintivo" (Warner, 2003). Estudos comparando várias populações da mesma espécie e espécies diferentes ocupando habitats semelhantes indicam que as condições ecológicas do ambiente podem afetar a existência e as características do mobbing (Alcock 1989; Griesser, 2003).

Em 1972, o médico sueco Peter Paul Heinemann, interessado no comportamento social infantil fora de sala de aula, toma de empréstimo da etologia o termo mobbing para descrever um comportamento altamente destrutivo de pequenos grupos de crianças, dirigido (na maioria dos casos) contra uma única criança.

$\mathrm{Na}$ década de 1980, o conceito de mobbing foi popularizado pelo psicólogo do trabalho Heinz Leymann, ale-

3 Segundo Alcock (1989), pode-se definir uma característica adaptativa como um traço herdado que proporciona ao indivíduo uma vantagem sobre outros com diferentes habilidades hereditárias, uma vantagem na transmissão de seus genes para as futuras gerações. 
mão, radicado na Suécia, considerado o "pai do mobbing" (Duque, Munduate \& Barea, 2003, p. 56). Ele retomou as observações realizadas anteriormente por Lorenz relacionando-as ao estudo da conduta humana nas organizações laborais. Nesta época, Leymann define mobbing

como o fenômeno no qual uma pessoa ou grupo de pessoas exerce violência psicológica extrema, de foram sistemática e recorrente e durante um tempo prolongado - por mais de seis meses e que os ataques se repitam numa freqüência média de duas vezes na semana - sobre outra pessoa no local de trabalho, com a finalidade de destruir as redes de comunicação da vítima ou vítimas, destruir sua reputação, perturbar a execução de seu trabalho e conseguir finalmente que essa pessoa ou pessoas acabe abandonando o local de trabalho (Leymann, 1990, p. 121).

Aparentemente, quando se analisa o conceito de mobbing proposto pela etologia e o fenômeno descrito por Leymann, não se identifica nenhuma semelhança ou pontos em comum. No entanto, a partir da descrição de Zapf (1999) e a análise feita por Vandekerckhove e Commers (2002) podese considerar que, em termos gerais, o mobbing organizacional pode ser visto com uma reação extrema de um indivíduo a uma situação estressora ou ameaçadora.

Assim, este comportamento anti-ético (Vandekerckhove $\&$ Commers, 2002) pode ser entendido como uma reação do indivíduo a uma ameaça potencial existente no seu ambiente de trabalho (neste caso, um colega, chefe ou subalterno), segundo sua própria interpretação, da mesma maneira que os animais reagem à presença de um predador. Portanto, a princípio, a semelhança entre o conceito etológico de mobbing e o mobbing no ambiente de trabalho parece ser mais de ordem morfológica; sendo que as implicações evolutivas e ecológicas propostas pela etologia provavelmente não se aplicam a esta situação. No entanto, uma abordagem evolucionista do mobbing no ambiente de trabalho poderia trazer novas contribuições para o seu entendimento.

Leymann (1996, p. 172) descreve o fenômeno como "um conflito cuja ação visa à manipulação da pessoa no sentido não amigável" e que essa ação pode ser analisada através de três grupos de comportamentos: 1) um grupo de ações se desenvolve quanto à comunicação com a pessoa atacada, tendendo à interrupção da comunicação; 2) outro grupo de comportamentos se assenta sobre tentativas de denegrir a reputação da pessoa atacada; 3 ) as ações do terceiro grupo tendem a manipular a dignidade profissional da pessoa agredida. Somente se estas ações forem realizadas propositalmente, freqüentemente e por muito tempo podem ser chamadas de "mobbing". Suárez (2002) acrescenta um quarto mecanismo aos citados por Leymann: a manipulação das contrapartidas laborais (Tabela 1).

Segundo Leymann (1997) para se falar em mobbing, o fenômeno deve compreender pelo menos uma das 45 formas de comportamento descritos no Leymann Inventory of Psychological Terrorization (LIPT), desenvolvido e validado pelo autor em 1990: a) ataques à vítima através de medidas organizacionais; b) ataques às relações sociais da vítima, com isolamento social; c) ataques à vida privada da vítima; d) violência física; e) ataques às atitudes da vítima; f) agressões verbais; e g) rumores sobre a reputação da pessoa. Para um diagnóstico mais completo sobre a existência do mobbing no plano individual, além da aplicação do LIPT, recomenda-se a realização de entrevista psicológica individual, a qual pode ser complementada pelo Questionário de Saúde Geral de Goldberg (Pasquali, 1999).

TABELA 1. Formas de expressão do mobbing

\begin{tabular}{|c|c|}
\hline GRUPOS DE AÇÕES & MECANISMOS \\
\hline \multirow{3}{*}{ Manipulação da comunicação da vítima } & $\begin{array}{l}\text { - Negação de informação relativa ao posto de trabalho, como as funções } \\
\text { e responsabilidades, os métodos de trabalho: a quantidade, qualidade e } \\
\text { prazos do trabalho a ser realizado. }\end{array}$ \\
\hline & - Comunicação hostil explícita, com críticas e ameaças públicas. \\
\hline & $\begin{array}{l}\text { - Comunicação hostil implícita, como o não dirigir palavra, ou negar } \\
\text { cumprimento. }\end{array}$ \\
\hline \multirow{3}{*}{ Manipulação da reputação da vítima } & $\begin{array}{l}\text { - Realização de comentários injuriosos, com ridiculizações públicas, } \\
\text { relativas ao aspecto físico ou às idéias ou convicções políticas ou } \\
\text { religiosas. }\end{array}$ \\
\hline & - Realização de críticas sobre o profissionalismo da vítima. \\
\hline & - Assédio sexual da vítima. \\
\hline \multirow{7}{*}{ Manipulação do trabalho da vítima } & - Aumento da sobrecarga de trabalho. \\
\hline & - Atribuição de trabalhos desnecessários, monótonos ou rotineiros. \\
\hline & - Atribuição de tarefas de qualificação inferior à da vítima (shunting). \\
\hline & - Atribuição de demandas contraditórias ou excludentes. \\
\hline & - Atribuição de demandas contrárias aos padrões morais da vítima. \\
\hline & - Não atribuição de tarefas. \\
\hline & - Negação dos meios de trabalho. \\
\hline \multirow[b]{2}{*}{ Manipulação das contrapartidas laborais } & - Discriminação no salário, nos turnos, jornada ou em outros direitos. \\
\hline & - Discriminação quanto ao respeito, o tratamento ou no protocolo. \\
\hline
\end{tabular}

Fonte: Leymann (1996); Suárez (2002). 


\section{A. M. Guimarães e A. O. Rimoli}

Embora os dados relativos a pessoas assediadas em seu local de trabalho sejam alarmantes, cabe destacar que esta situação afeta também as pessoas que, sem serem as vítimas diretas, testemunham e observam episódios de assédio em seu local de trabalho. $\mathrm{O}$ fato de alguém ser testemunha do assédio é um preditor bastante significativo do estresse geral e das reações ao mesmo (Vartia, 2001).

Segundo Piñuel y Zabala (2001, p. 32 ) o assédio laboral tem como objetivo:

(...) intimidar, diminuir, humilhar, amedrontar e consumir emocional e intelectualmente a vítima, com o objetivo de eliminá-la da organização ou satisfazer a necessidade insaciável de agredir, controlar e destruir que é apresentada pelo assediador que aproveita a situação organizacional particular (reorganização, redução de custos, burocratização, mudanças drástica, etc.) para canalizar uma série de impulsos e tendências psicopáticas.

O mesmo autor acrescenta que os assediadores fazem funcionar o aparato devastador do mobbing através de ciúme e inveja, sendo esta última não somente canalizada para os bens materiais da vítima, mas para suas qualidades pessoais positivas, tais como, sua inteligência, brilho pessoal, equanimidade, entre outros. Esta situação ocorre, sobretudo, quando são incorporados novos e jovens trabalhadores, os quais ameaçam uma eventual promoção profissional e a permanência do assediador na organização. Também é habitual que os ataques se produzam porque a vítima tem certas características diferentes do restante do grupo, e.g., sua cor de pele ou qualquer outra característica física. Este é um tipo de agressão extremamente sutil enquanto perverso, já que se trata de um comportamento premeditado, que se executa segundo uma estratégia minuciosamente preconcebida, com o objetivo claro e concreto de anulação (destruição) da vítima.

Embora Leymann (1996) tenha analisado como objeto de mobbing uma vítima isolada, diversos estudos têm mostrado que só uma minoria de afetados informa ter sido objeto de assédio psicológico individualmente, e uma maioria informa que tenha compartilhado sua experiência com alguns colegas e inclusive, em alguns casos, com todo seu grupo de trabalho (Hoel, Cooper \& Faragher, 2001; Liefooghe \& Olafsson, 1999; Rayner, 1997).

Enquanto Leymann (1992) refere que a personalidade do assediado é irrelevante frente ao fenômeno de $m o b$ bing, outros autores como Matthiesen e Einarsen (2001) afirmam que apesar de Leymann estar correto, os dados obtidos através de suas pesquisas mostram que algumas vítimas são mais sensíveis ao mesmo e reagem de maneira mais dramática que outras frente às situações do assédio. Isso confirma a diversidade com que as pessoas, inclusive as vítimas de assédio, podem reagir diante de conflitos interpessoais e ao escalonamento do conflito no trabalho (Medina, Dorado, Munduate, Arévalo \& Cisneros, 2002; Munduate, Ganaza, Peiró \& Euwema, 1999; Zapf $\&$ Gross, 2001).

Vartia (2001) refere que a maioria dos estudos sobre mobbing considera sua duração como relativamente longa, com um tempo de exposição de mais de 12 meses. Zapf e Gross (2001) em revisão de vários trabalhos sobre o tema, verificaram uma duração mínima de seis meses até, aproximadamente, quatro anos e acrescentam que em um estudo finlandês, $30 \%$ das vítimas informaram um tempo de exposição ao mobbing de cinco anos ou mais.

\section{Delimitação do Conceito}

Devem ser excluídas do diagnóstico de mobbing as seguintes situações: o estresse causado pela premência de tempo na execução de algum trabalho ou a competitividade empresarial existente, ter um mau dia, manter conflito com um colega e sofrer por causa de um chefe exigente ou perfeccionista. Ficam também descartados os atritos habituais, as tensões e os incidentes isolados que são próprios das organizações modernas nas quais o incremento do grau de interdependência entre os atores leva a numerosas situações de desencontro. Este tipo de desencontro não constitui mobbing ou psicoterrorismo. Sobre esta questão, Leymann faz, no seu livro "Mobbing" (1990, p. 8) uma importante constatação:

(...) os conflitos são inevitáveis (...) não estamos falando aqui, do conflito. Nos referimos a um tipo de situação comunicacional que ameaça infligir ao individuo graves prejuízos psíquicos e físicos. O mobbing é um processo de destruição; compõe-se de uma série de atuações hostis que, se vistas de forma isolada, poderiam parecer anódinas, mas cuja repetição constante tem efeitos perniciosos.

O mobbing se diferencia do assédio sexual e ou racial e das agressões ou violências físicas, as quais têm outras manifestações e efeitos. Embora as evidências demonstrem que o mobbing e o assédio sexual sejam fenômenos distintos, apesar da passagem de um para o outro ser freqüente, atenção deve ser dada à colocação de Hirigoyen (1998/2000). Esta autora assinala que as mulheres não somente são vítimas com maior freqüência que os homens, mas que o assédio dirigido às mesmas é diferente, já que constantemente tem conotações sexuais ou "machistas". No entanto, nos dois casos, humilha-se ao outro, considerado um objeto à disposição.

Quanto à especificidade do assédio dirigido às mulheres, segundo Hirigoyen, por um lado, estão as mulheres que rejeitam as investidas de um superior ou de um colega e que como consequiência são marginalizadas, humilhadas ou tratadas com rudeza. Por outro lado, depara-se com a discriminação da mulher: algumas são marginalizadas ou assediadas, ou simplesmente impedidas de trabalhar, pelo fato de serem mulheres. O Comitê Econômico e Social Francês reconhece que as circunstâncias relacionadas ao assédio sexual apresentam semelhanças importantes com as de mobbing, e.g., quanto às dificuldades enfrentadas pela vítima na hora de se expressar, defender-se e apresentar denúncias, provas ou encontrar testemunhas (Hirigoyen, 2000/2002).

Por outro lado, recentes pesquisas apontam que o fenômeno pode ocorrer igualmente, tanto entre trabalhadores sem cargos de chefia, quanto em supervisores, gerentes e funcionários de alto escalão e que as mulheres em cargos administrativos são significativamente mais expostas ao risco de mobbing que sua contrapartida masculina (Hoel \& Cooper, 2001). Na Inglaterra, Irlanda, Áustria e Itália foram encontrados altos níveis de mobbing perpetrados por gerentes (75\% ou mais). Em contraste, na Finlândia, Alemanha e Portugal, os colegas de trabalho (mesmo nível hierárquico), freqüentemente ( $70 \%$ ou mais), eram os assediadores (mobbers) (ILO, 2000). 


\section{Epidemiologia}

Na Suécia, na década de 1980, a prevalência do mobbing era da ordem de 3.5\% (Leymann, 1992). A Fundação Européia para a melhoria das condições de vida e trabalho, em pesquisa realizada em abril de 1997 relata que o mobbing pode afetar a cada ano, 12 milhões de empregados europeus, com uma incidência de $10 \%$ em trabalhadores temporários. Em 2002, a Espanha passa de 5,5\%, dos 12 milhões de 1997 , para a alarmante cifra de $11.4 \%$ dos casos europeus. A Organização Internacional do Trabalho (OIT), em 1998, estimou uma prevalência de mobbing na Europa de 5,0\% e após um ano, um aumento para 7\% (ILO, 2000). No Brasil, Guimarães e Vasconcelos (2004), estudando mobbing em trabalhadores do gasoduto Brasil-Bolívia sediados em Corumbá (MS), encontraram uma prevalência anual de 7,0\%.

Segundo Di Martino (2002a), a prevalência de mobbing varia de $1 \%$ a mais de $50 \%$ dependendo do método utilizado, da ocupação ou setor, como também do país de ocorrência. Quando o mobbing é avaliado a partir de uma definição precisa, e refere-se a uma experiência regular, o mesmo é encontrado em 5\% da população. Quando são incluídas experiências ocasionais de mobbing, índices ao redor de $10 \%$ são alcançados. Nos casos nos quais são consideradas vítimas de mobbing aquelas que experimentaram um ou mais comportamentos negativos, índices entre $10 \%$ e $40 \%$ foram obtidos.

Além disso, pode haver diferença de incidência de mobbing segundo o setor de atuação. Hubert e Veldhoven (2001) constataram diferença significativa entre os 12 setores de atuação estudados, sendo que, aqueles que apresentaram maior tendência para exibirem comportamentos indesejáveis sistemáticos foram: educação, indústria e setores ligados a atividades recreativas, culturais ou ambientais. As porcentagens de ocorrência (às vezes, freqüentemente ou sempre) de comportamentos agressivos ou indesejáveis de colegas ou chefe estiveram entre $6,5 \%$ (instituições financeiras) e 56,2\% (setores ligados à recreação, cultura e meio ambiente).

\section{Tipos de Mobbing}

A maior parte dos autores concorda com a existência de três tipos de assédio:

Ascendente: Uma pessoa que pertence a um nível hierárquico superior da organização, se vê agredida por um ou vários subordinados. Geralmente, o início se dá quando alguém de fora é introduzido na empresa em um cargo superior, porque seus métodos não são aceitos pelos trabalhadores que se encontram sobre seu comando ou porque este cargo é desejado por algum deles. Outra modalidade seria aquela em que um(a) trabalhador(a) é alçado(a) a um cargo de responsabilidades em virtude do qual se outorga a capacidade de organizar e comandar seus antigos companheiros. A situação se complica se, previamente, os demais trabalhadores não foram consultados e não estão de acordo com a promoção, ou se o novo responsável não deixar claros os objetivos do setor, ocasionando intromissões nas funções de alguma(s) pessoa(s). Em menor proporção, o mobbing pode ser desencadeado contra aqueles chefes que se mostram autoritários e arrogantes no contato interpessoal.

Horizontal: O comportamento dos grupos não é o resultado dos comportamentos individuais das pessoas que os compõem, mas o grupo aparece com uma nova identidade que tem seu próprio comportamento. Nesta direção, um trabalhador(a) se vê assediado(a) por um companheiro com o mesmo nível hierárquico, embora seja possível, se bem que não oficialmente, que tenha uma posição de fato, superior. $\mathrm{O}$ ataque pode ocorrer por problemas puramente pessoais, ou porque alguns dos membros do grupo não aceitam as normas de funcionamento tacitamente ou expressamente aceitas pelos demais. Outra circunstância que dá lugar a este comportamento é a existência de pessoas frágeis do ponto de vista físico e/ou psíquico ou diferentes, sendo estas diferenças exploradas pelos demais simplesmente para passar o tempo ou proporcionar aborrecimentos.

Descendente: Situação mais habitual. Trata-se de um comportamento no qual a pessoa que detém o poder, através de depreciação, falsas acusações, insultos e ofensas, mina a esfera psicológica do trabalhador assediado para se destacar frente a seus subordinados, para manter sua posição hierárquica. Pode também tratar-se simplesmente de uma estratégia empresarial cujo objetivo é forçar o abandono "voluntário" de uma determinada pessoa sem recorrer à sua demissão legal, já que não haveria justificativa objetiva para tal, o que acarretaria custos econômicos para a empresa.

\section{Fases do Mobbing}

É tarefa complexa estabelecer uma seqüência típica de fatos no decorrer de um processo de assédio psicológico no trabalho que permita determinar uma série fixa de fases, abrangendo desde seu início até o desfecho, qualquer que seja. Esta impossibilidade se deve, sobretudo, às peculiaridades que em cada caso, os assediadores possam apresentar, as vítimas, o meio e contexto no qual o conflito se desenvolva, assim como o modelo de organização no qual o processo se inicia. Não obstante, Leymann (1990) desenvolveu a partir de suas experiências quatro fases que se dão habitualmente nestes processos:

$\mathbf{1}^{\mathbf{a})}$ Fase de conflito: Conflitos interpessoais normais entre pessoas com interesses e objetivos distintos ou até mesmo incompatíveis geram problemas pontuais, atritos e choques entre as pessoas, os quais poderiam ser resolvidos de forma positiva através do diálogo. Caso contrário, quando estes conflitos pontuais começam a estigmatizar-se, se produz um ponto de inflexão nas relações, constituindo-se em ponto de partida de uma escalada de enfrentamentos.

$\left.2^{a}\right)$ Fase de mobbing ou de estigmatização: Nesta fase, o assediador põe em prática toda uma estratégia de humilhações de sua vítima, utilizando para isso, sistematicamente e durante um tempo prolongado, uma série de comportamentos perversos, cujo objetivo é ridicularizar e isolar socialmente a vítima. Esta segunda fase já é propriamente o mobbing. A vítima não consegue acreditar no que está acontecendo e pode chegar inclusive à negação das evidências mediante passividade ou a evitação do fenômeno para o resto do grupo ao qual pertence. Esta fase é de grande duração (segundo Leymann, de um a três anos) e serve para estigmatizar a vítima com o consentimento e inclusive com a colaboração ativa ou passiva do meio.

$3^{\mathbf{a}}$ ) Fase de intervenção na empresa: A direção da empresa toma conhecimento do conflito, caso não se trate de uma estratégia empresarial pré-concebida, na qual a origem do problema estaria na própria empresa. Duas formas de atuação podem ser postas em prática, geralmente pelo departamento de recursos humanos ou pela direção de pessoal:

- Solução positiva do conflito - Em uma pequena parte dos casos, a direção da empresa, ao tomar conhecimento do problema, realiza uma investigação exaustiva do mesmo e decide que o(a) trabalhador(a) ou o(a) assediador(a) seja transferido de seu posto de trabalho, descobre a estratégia de 
humilhações utilizada e articula mecanismos para que a mesma não volte a ocorrer, punindo neste caso o(a) assediador(a);

- Solução negativa do conflito - Normalmente e sem ter um conhecimento exaustivo do caso, devido à sua nula ou escassa investigação, a direção somente encara a vítima como o problema a ser combatido, destacando suas características individuais distorcidas e manipuladas, sem reparar que a origem do mesmo está em outro fator. Desta maneira, a direção da empresa soma-se ao meio que assedia ativa ou passivamente a vítima.

$4^{\text {a) }}$ Fase de marginalização ou exclusão da vida laboral: Esta última fase se encerra com a vítima abandonando seu emprego, muito provavelmente depois de haver passado por vários e prolongados períodos de licença. Os(as) trabalhadores(as) das administrações públicas defrontam-se ao pedir mudanças do local de trabalho, com poucas ocasiões nas quais as mesmas se materializam. Nas empresas privadas parte das vítimas decide permanecer/agüentar heroicamente em seu posto de trabalho passando por um calvário que tem consequiências deletérias para sua saúde. Alguns sofrem o agravamento do problema, tanto dentro como fora da empresa. Nos casos mais extremos, os trabalhadores(as) assediados podem chegar ao suicídio.

Piñuel y Zabala (2003) inclui uma fase a mais que estaria entre a $3 \mathrm{a}$ e $4 \mathrm{a}$ de Leymann e que denomina de "Fase de solicitação de ajuda especializada externa e diagnóstico incorreto", assinalando que não existem especialistas que possam abordar um problema cuja origem está na empresa e não na vítima.

\section{Fatores de Risco}

Para poder identificar fatores de risco e assim prevenir a violência no trabalho é importante que se entendam suas causas e antecedentes. A natureza da relação entre variáveis individuais, situacionais e organizacionais, e violência/assédio é, até certo ponto, aberta a várias interpretações. Devido à natureza transversal da maioria das pesquisas neste campo, uma relação causal entre estas variáveis e violência/ assédio não pode ser estabelecida; porém, a existência de uma relação entre as mesmas, pode. As variáveis discutidas, em geral, são entendidas como "fatores contribuintes" para o aumento da probabilidade de ocorrência da violência em um ambiente de trabalho. Refletindo um desenvolvimento neste campo do conhecimento, o foco está nos fatores ligados à situação e organizacionais, enquanto se reconhece o impacto dos aspectos individuais e dos fatores socioeconômicos (Chappell \& Di Martino, 1999; Leather, Brady, Lawrence, Beale \& Cox, 1999).

Segundo Menchón (2000), as causas para o aparecimento do mobbing como risco ocupacional devem ser buscadas em fatores de risco psicossocial relacionados ao ambiente de trabalho, em uma inadequada gestão dos conflitos interpessoais por parte dos superiores e nos fatores de risco derivados da organização do trabalho.

Hoel, Cooper e Faragher (2001) referem que a despeito da escassez de evidências, um corpo substancial de pesquisas foi realizado na última década, sugerindo evidências de que o "mobbing" é um importante e autêntico risco psicossocial no ambiente de trabalho, com implicações negativas para indivíduos e organizações.

Zapf e Gross (2001) acrescentam que o mobbing no contexto da teoria do estresse é considerado como um estressor social grave. É provável que explicações unilaterais quanto às causas do mobbing sejam impróprias e que muitos casos sejam, de fato, caracterizados pela multi-causalidade, um achado comum em pesquisas desta natureza (Zapf, 1999).

\section{Efeitos Adversos à Saúde}

Pesquisas desenvolvidas com o objetivo de investigar os efeitos do mobbing sugerem que esta situação reduz a saúde psicológica e física de suas vítimas e afeta negativamente seu bem-estar e a eficiência de outros trabalhadores, ao mesmo tempo em que instala a negligência, o absenteísmo e um aumento expressivo do pedido de licenças médicas e afastamentos por doença (Zapf, Einarsen, Hoel \& Vartia, 2003).

Nesta direção, sintomas típicos associados à tensão foram relatados como associados ao mobbing no trabalho, tais como insônia, melancolia e apatia. (Björkqvist, Österman \& Hjelt-Bäck, 1994; Quine, 1999). Segundo O'Moore, Seigne, Mcguire e Smith (1998), 40\% das vítimas pesquisadas informam que o mobbing afetou sua saúde física e $43 \%$ sua saúde mental e, como conseqüência destes, $26 \%$ e $92 \%$, respectivamente, tinham procurado tratamento médico, psiquiátrico ou outra ajuda profissional. Os autores acrescentam que uma entre cinco pessoas relatou estar em uso de medicamentos como conseqüência da experiência.

Di Martino (2002b) refere que várias pesquisas constataram um aumento de estresse e tensão e diminuição do bem-estar psicológico, resultantes do processo de mobbing. Estas elencam os principais efeitos adversos da violência psicológica na saúde: ansiedade, depressão, sintomas psicossomáticos, agressividade, desconfiança, prejuízos cognitivos, tais como, dificuldade de concentração ou de pensar claramente, reduzida capacidade para a resolução de problemas, isolamento e solidão, deterioração das relações interpessoais e transtorno por estresse pós-traumático. Alterações como o transtorno obsessivo, o transtorno bipolar, a depressão e a ansiedade, também foram relatados (Agust \& Beas, 2001; González de Rivera, 2001; Leymann, 1997; Piles de la Fuente, 2001).

Em um estudo realizado com trabalhadores de um hospital austríaco, Niedl (1996) afirma que indivíduos que referiam estar sob o processo de mobbing, evidenciaram maiores índices de depressão, queixas psicossomáticas, ansiedade e irritabilidade em um nível estatisticamente significativo, do que aqueles que não estavam sob o processo. Dados semelhantes foram achados em vários outros estudos, e.g., na Alemanha (von de Mackensen Astfeld, 2000) e na Dinamarca (Mikkelsen \& Einarsen, 2001). Baseado em um estudo sueco, em nível nacional, Leymann (1992) concluiu que alguns sintomas psicoemocionais, (como irritabilidade, agressividade, prejuízos relativos à memória e à concentração) e outros de origem psicossomática (como desconforto gástrico, perda de apetite e náusea) diferenciaram marcadamente trabalhadores com mobbing e sem mobbing.

Autores como Cervera e colaboradores (2001) e Pérez de Heredia, González, Ramírez, Imaz e Ruiz (2001) corroboram os dados de Leymann (1992) sobre as repercussões do mobbing na saúde física e mental dos trabalhadores alertando para a possibilidade da ocorrência de condutas anti-sociais com tendência a adição a drogas, ou consumo de tabaco e abuso de álcool. Bobes, González e Sainz, (1998) e Leymann (1997) também referem risco de exposição a condutas autolesivas, como conflitos familiares, divórcios e inclusive suicídios, até alterações de ordem fisiológica como a hipertensão. Bruziches e Rinaldi (2000) relatam a ocorrência de problemas dermatológicos, enquanto D'Elia (1997) e Leymann (1997) falam em alterações digestivas. Já Mahler, Schmidt, Fartasch, Loew e Diepgen (1998) observam uma certa tendência para a exposição do trabalhador submetido a mobbing ao risco de 
acidentes vasculares e coronarianos.

\section{Prevenção}

Trata-se de abordar o mobbing a partir de uma visão sistêmica, global e dinâmica, considerando-o, por sua vez, articulado a um contexto social concreto e determinante (Peiró, 1983). Esta aproximação sistêmica ao mobbing implica em analisar um considerável número de aspectos relacionados ao fenômeno. Dada sua complexidade, a abordagem do fenômeno social do mobbing requer um enfoque multidisciplinar, tanto em sua conceituação como na intervenção para sua prevenção e tratamento. Estas intervenções podem se concretizar em dois campos: a resolução da situação de assédio psicológico e a abordagem das conseqüências do assédio para o próprio sujeito.

Da organização do trabalho se requer como um primeiro eixo estratégico para a abordagem do mobbing, o estabelecimento de planos preventivos, tanto de informação e formação como de implementação de adequados Protocolos de Ação. Estes Protocolos permitiriam orientar a abordagem dos seguintes aspectos: a) Criar uma cultura organizacional que minimize e evite o mobbing; b) Gerar estilos de gestão do conflito e de liderança participativos; c) Dotar as potenciais vítimas de instrumentos de comunicação formal do problema na organização; e d) Dispor de indicadores que circunscrevam a situação da organização com relação ao assédio psicológico, do mesmo modo dado aos acidentes de trabalho. Sugere-se ainda o planejamento de estratégias para a avaliação dos riscos psicossociais da organização do trabalho, a avaliação dos riscos ocupacionais de origem psicológica, psicossocial e organizacionais, e a criação e execução de projetos e planos para o desenvolvimento da qualidade de vida profissional.

O segundo eixo de tratamento do assédio psicológico na organização requer ativar Planos de Ação paliativos dos efeitos do mobbing e curativos das consequiências que este processo tenha causado aos assediados. $\mathrm{O}$ assediado necessita, na maior parte dos casos, de tratamento de urgência. Para tanto, deverão intervir de maneira coordenada e multidisciplinar, os profissionais que contribuirão para a resolução do problema - psicólogos, advogados, médicos, assistentes sociais, entre outros. Este tratamento deve se iniciar a partir de diagnóstico psicológico que estabeleça a estratégia terapêutica a ser seguida frente à análise da sintomatologia apresentada pelo afetado, na qual se combinem ao mesmo tempo os serviços especializados do campo jurídico (Blanco \& López, 2002; Velásquez, 2001) para fazer frente aos complexos pormenores do procedimento ou ações legais a empreender.

A concomitância das intervenções psicológica e jurídica, como medida para evitar que o dano continue avançando, possibilitará o fortalecimento da auto-estima e da identidade da pessoa, ajudando-a a recuperar suas emoções positivas articuladas à percepção da auto-eficácia (Cisneros, Medina, Munduate \& Dorado, 2000). Estas medidas individuais, a que o sujeito objeto de assédio psicológico pode recorrer, só deveriam ser a ante-sala de um futuro desenvolvimento do enfrentamento do problema em um nível global e sistêmico que sincronize, em primeira instância, os esforços individuais, organizacionais e sociais para eliminar o problema do mobbing.

É surpreendente que algo tão simples, tão evidente e constatado, ou seja, a relação direta existente entre o sucesso empresarial e as relações interpessoais, ainda não tenha sido apreciada pela grande maioria do empresariado.
Encontramos-nos, portanto, ante uma situação laboral que se caracteriza por elevados custos humanos, econômicos e sociais, e cujos indicadores mais relevantes podem ser concretizados nos seguintes aspectos: uma perda de potencial profissional para as organizações, um prejuízo difícil de ser reparado no estado de saúde da vítima, uma provável deterioração de suas relações pessoais e familiares e um custo altíssimo ao sistema de saúde e benefícios relacionados.

\section{Considerações Finais}

A complexidade do fenômeno "mobbing" como um campo de estudos emergiu recentemente. Há a necessidade de uma homogeneidade da terminologia e conceituação utilizadas de forma a poderem ser compartilhadas por diferentes pesquisadores de diferentes áreas do conhecimento, possibilitando a não fragmentação dos conhecimentos obtidos. Quanto à semelhança dos conceitos etológico e psicológico de mobbing, verificou-se que os mesmos guardam especificidades, sobretudo em relação às implicações evolutivas e ecológicas propostas pela etologia. Pode-se dizer que a princípio, a semelhança entre os conceitos é de ordem morfológica, somente. Uma abordagem evolucionista do mobbing no ambiente de trabalho, no entanto, poderia trazer novas contribuições para o seu entendimento.

Os atos de violência no trabalho provocam uma alteração imediata e geralmente duradoura das relações interpessoais, da organização do trabalho e do entorno laboral em seu conjunto.

Aos empresários recai o custo direto do trabalho perdido e a necessidade de melhorar as medidas de segurança. Entre os custos indiretos podem ser citados: uma menor eficiência e produtividade, a redução da qualidade dos produtos, a perda de prestígio da empresa e a diminuição do número de clientes.

Conclui-se que o "mobbing" ou assédio psicológico no trabalho é uma síndrome psicossocial multidimensional: sindrome porque se apresenta comumente com um complexo de sintomas físicos e psíquicos específicos e inespecíficos não redutíveis a uma configuração típica e facilmente diagnosticável; psicossocial porque afeta o indivíduo, o grupo de trabalho e a organização produzindo disfunções em nível individual e coletivo e multidimensional porque se origina e desenvolve permeando e afetando a todos os níveis hierárquicos da organização e também com importantes repercussões externas.

\section{Referências}

Alcock, J. (1989). Animal Behavior: an evolutionary approach. Massachusetts: Sinauer Associates.

Anderson, J. (2001). Informe sobre el acoso moral en el lugar de trabajo. Resolución del Parlamento Europeo sobre el acoso moral en el trabajo. Acta A5-0283 del 16/07/2001. Retirado em 20/03/2005 de http://www.mobbing.nu .

Agust, S. \& Beas, M. (2001). Burnout en mujeres: un estudio comparativo entre contextos de trabajo y no trabajo. Ansiedad y Estrés, 3 (1), 79-88.

Barreto, M. (2000). Uma Jornada de Humilhações. Dissertação de Mestrado, Pontifícia Universidade Católica de São Paulo, São Paulo.

Bartecki, U. \& Heymann, E. W. (1987). Field observation of snake-mobbing in a group of saddleback tamarins, Saguinus fuscicollis nigrifrons. Folia Primatologica, 48 (3-4), 199202. 


\section{A. M. Guimarães e A. O. Rimoli}

Björkqvist, K., Österman, K. \& Hjelt-bäck, M. (1994). Aggression among university employees. Aggressive Behaviour, 20, 173-84.

Blanco, M. J.\& López, F. J. (2002). La vía penal integrada en el Tratamiento de Urgencia contra el acoso moral en el trabajo. Retirado em 18/08/2004, de http://www.laley.net

Bobes, J., Gonzalez, J. C. \& Sainz, P. (1998). Prevención de las conductas suicidas y parasuicidas. Barcelona: Masson.

Bruziches, D. \& Rinaldi, B. (2000). Job Safety: Where There is High Tension at the Work Place: Mobbing, Professioni Infermieristiche, 3(1), 46-49.

Chappell, D. \& Di Martino, V. (1999). Violence at work. AsianPacific Newsletter on Occupational Health and Safety, 6(1), 132-153

Cervera, G., Haro, G., Martinez-Raga, M., Bolinches, F., De Vicente, P. \& Valderrama, J. C. (2001). Los trastornos relacionados con el uso de sustancias desde la perspectiva de la psicopatología y las neurociencias. Trastornos Adictivos, 7(3), 164-171.

Cisneros, I., Medina, F. J., Munduate, L. \& Dorado, M. A. (2000). Consecuencias emocionales de la autoeficacia en situaciones de negociación. Apuntes de Psicología, 18, 97-121.

D'elia, R. (1997). Mobbing, also among health personnel? Krankenpfl Soins Infirm, 90(8), 74-77.

Di Martino, V. (2002a). Work-related violence. New York: Westdeutscher Verlag Wesbaden and Westview Press.

Di Martino, V. (2002b). Workplace violence in the health sector: country case studies. Synthesis Report, International Labour Organisation/International Council of Nurses, World Health Organisation \& Public Services Internationale Joint Programme, Geneva.

Duque, B. M., Munduate, L. \& Barea, M. J. B. (2003) La espiral del mobbing. Papeles del Psicólogo, 14, 55-61.

Garavaglia, R. (2000). Le houspillage ou mobbing: sássocier pour faire fuir lénnemi. Retirado em 20/11/2004, de http:// www.ornithomedia.com/pratique/debuter/debut_art31_ 1.htm

Gonzalez de Rivera, J. L. (2001). El síndrome de acoso institucional. Retirado em 16/08/2004, de http://www. psiquiatria.com/articulos/psiqsocial/2781/

Griesser, M. (2003). Nepotistic vigilance behavior in Siberian jay parents. Behavioral Ecology, 14, 246-250.

Guimarães, L. A M. \& Vasconcelos, E. (2004, julho). Mobbing: assédio psicológico no em trabalhadores do gasoduto BrasilBolívia. Trabalho apresentado no I Congresso Brasileiro de Psicologia Organizacional e do Trabalho. Salvador, Brasil.

Hirigoyen, M. F. (2000). Assédio Moral: a violência perversa no cotidiano. (M. H. Kühner, Trad.) Rio de Janeiro: Bertrand Brasil. (Trabalho original publicado em 1998)

Hirigoyen, M. F. (2002). Mal-estar no Trabalho: redefinindo o assédio. (R. Janowitzer, Trad.) Rio de Janeiro: Bertrand Brasil. (Trabalho original publicado em 2001)

Hoel, H. \& Cooper, C. (2001). Origins of bullying: theoretical frameworks for explaining workplace bullying. Em N. Tehrani (Org.), Building a culture of respect: Managing bullying at work (pp.45-53). London: Taylor \& Francis.

Hoel, H., Cooper, C. \& Faragher, B. (2001). The experience of bulling in Great Britain: The impact of organizational status. European Journal of Work and Organizational Psychology, 10, 443-466.
Hubert, A. B. \& Veldhoven, M. V. (2001). Risk sectors for undesirable behavior and mobbing. European Journal of Work and Organizational Psychology, 10 (4), 415-424.

ILO/ICN/WHO/PSI (2000). Framework Guidelines on Workplace Violence in the Health Sector, Geneva.

Iwamoto, T., Mori, A., Kawai, M. \& Bekele, A. (1996). Antipredator behavior of gelada baboons. Primates, 37(4), 389-397.

Leather, P. (2001). Workplace violence: scope, definition and global context. Em L.C. Cooper \& N. Swanson (Orgs), Violence in the health sector: State of the art (pp. 3-18). Geneva: International Labour Office- ILO. Retirado em 10/05/2004 de http://www.icn.ch/state.pdf .

Leather, P., Brady, C., Lawrence, C., Beale, D. \& Cox, T. (1999). Work-related Violence: Assessment and Intervention. London: Routledge,

Leymann, H. (1990). Mobbing and psychological terror at workplaces. Violence and Victims, 5, 119-126.

Leymann, H. (1992). Vuxenmobbning på svenska arbeidsplatser, Delrapport 1 om frekvenser [Adult bullying at Swedish workplaces: Report 1 concerning frequencies]. Stockholm: Arbetarskyddstyrelsen,

Leymann, H. (1996). The content and development of mobbing at work. European Journal of Work and Organisational Psychology, 5(2), 165-84.

Leymann, H. (1997). The Definition of Mobbing at Workplaces. The Mobbing Encyclopaedia. Bullying. Retirado em 24/09/2004, de http://www.leymann.se

Liefooghe, A. P. D. \& Olafsson, R. (1999). 'Scientists' and 'amateurs': mapping the bullying domain. International Journal of Manpower, 20(1/2), 32-43.

Mahler, V., Schmidt, A., Fartasch, M., Loew, T. H. \& Diepgen, T. L. (1998). Value of psychotherapy in expert assessment of skin diseases. Recommendations and indications for additional psychotherapy evaluation in expert assessment from the viewpoint of dermatology. Hautarzt, 49(8), 626-633.

Matthiesen, S. B. \& Einarsen, S. (2001). MMPI-2 configurations among victims of bulling at work. European Journal of Work and Organizational Psychology, 10, 467-484.

Medina, F. J., Dorado, M. A., Munduate, L., Arévalo, A. \& Cisneros, I. (2002). Secuencias conductuales en la efectividad de la gestión del conflicto. Psicothema, 14, 79-88.

Menchón, E. (2000). El riesgo psicosocial. Qué es y cómo se previene. Prevención, 151, 7-16.

Mikkelsen, E. G. \& Einarsen, S. (2001). Bullying in Danish worklife: prevalence and health correlates. European Journal of Work and Organizational Psychology, 10(4), 393- 413.

Munduate, L., Ganaza, J., Peiró, J. M. \& Euwema, M. (1999). Profiles of Conflict Handling Styles and Efectiveness. International Journal of Conflict Management, 10(1), 1-98.

National Institute of Occupational Security and Health -NIOSH(2003). Violence in the Workplace: Risk factors and Prevention Strategies. Retirado em 20/08/2004, de http://www.cdc.gov/ niosh/violrisk.html

Niedl, K. (1996). Mobbing and well-being: Economic and personnel development implications. European Journal of Work and Organisational Psychology, 5, 239-49.

O'Moore, M., Seigne, E., Mcguire, L. \& Smith, M. (1998). Victims of bullying at work. Ireland Journal of Occupational Health and Safety: Australia and New Zealand, 14, 569-74. 
Owings, D. \& Coss, R. G. (1977). Snake mobbing by California ground squirrels: adaptive variation and ontogeny. Behaviour, 62(1/2), 50-69.

Paoli, P. \& Merllié, D. (2001). Third European survey on working conditions 2000, Publisher: European Foundation for the Improvement of Living and Working Conditions, Luxembourg: Office for Official Publications of the European Communities.

Passamani, M. (1995). Field observation of a group of Geoffroy's marmosets mobbing a margay cat. Folia Primatologica, 64(3), 163-166.

Pasquali, L. (1999). Princípios de Elaboração de Escalas Psicológicas. Em C. Gorenstein, L. H. S. G. Andrade \& A. W. Zuardi (Orgs), Escalas de Avaliação Clínica em Psiquiatria e Psicofarmacologia (pp.15-22). São Paulo: Lemos Editora.

Peiró, J. M. (1983). Psicología de las organizaciones. Madri: UNED.

Perez de Heredia, J. L., Gonzalez, A., Ramirez, M., Imaz, A. \& Ruiz, J. (2001). Abuso y dependencia de sustancias en el trastorno bipolar. Trastornos Adictivos, 5(3), 19-24.

Piles de la Fuente, P. (2001). Interviene el estrés en el trastorno bipolar? Interpsíquis, 2. Retirado em 18/08/2004, de http:// www.psiquiatria.com/artículos/trastorno_bipolar/2135/

Piñuel y Zabala, I. (2001). Como sobrevivir al acoso psicológico en el trabajo. Santander: Sal Terrae.

Piñuel y Zabala, I. \& Cantero, A. O. (2003). La incidencia del mobbing o acoso psicológico en el trabajo en España. Lan Harremanak: Revista de Relaciones Laborales, 7(2), 35-62

Quine, L. (1999). Workplace bullying in NHS community trust: staff questionnaire survey. British Medical Journal, 318, 228-32.

Rayner, C. (1997). The incidence of workplace bulling. Journal of Community and Applied Social Psychology, 7(3), 199-208.

Richard, A. F. (1985). Primates in nature. New York: W. H. Freeman.

RSPB-The Royal Society for the Protection of Birds (s/d). Mobbing. Retirado em 20/11/2004, de http//www.rspd.org.uk/birds/ advice/mobbing/index.asp

Srivastava, A. (1991). Cultural transmission of snake-mobbing in free-ranging Hanuman langurs. Folia Primatologica, 56(2), 117-120.
Suárez, O. A. (2002). La violencia psicológica en el lugar de trabajo en el marco de la unión europea. Lan Har Remanak, 7, 279-296.

Vandekerckhove, W. \& Commers, R. (2002, August). Downward Workplace Mobbing: a Sign of the Times? Conference Paper presented at European Ethics Summit 2002, European Parliament, Brussels.

Vartia, M. (2001). Consequences of workplace bulling with respect to the well-being of its targets and the observers of bullying. Scandinavian Journal of Work and Environment and Health, 27(1), 63-69.

Velásquez, M. (2001). La respuesta jurídico legal ante el acoso moral en el trabajo o Mobbing. Retirado em 18/08/2004, de http://www.uvigo.es/webs/ccoo/AcosoMoralTraballo.pdf

Von de Mackensen Astfeld, S. (2000). Das Sick-Building-Syndrom unter besonderer Berücksichtigung des Einflusses von Mobbing. Verlag Dr. Kovac, Hamburg.

Warner, D. (2003). Mob warfare on the wing. Irish.examiner. com Retirado em 20/11/2004, de http://www.irishexaminer. com/text

Zapf, D. (1999). Organisational, work group related and personal causes of mobbing/bullying at work. International Journal of Manpower, 20 (1/2), 70-85.

Zapf, D. \& Gross, C. (2001). Conflict escalation and coping with workplace bullying: A replication and extension. European Journal of Work and Organisational Psychology, 10, 497522.

Zapf, D., Einarsen, S., Hoel, H. \& Vartia, M. (2003). Empirical Findings on Bullying in the Workplace. Em S. Einarsen, H. Hoel, D. Zapf \& C. L. Cooper (Orgs), Bullying and emotional abuse in the workplace. International perspectives in research and practice, (pp.222-241). London/New York, Taylor and Francis. 
